\title{
Found in Translation: Collaborative Contemplations of Tibetan Buddhism and Western Science
}

\author{
Kelsey M. Gray ${ }^{1}$, Dadul Namgyal ${ }^{1}$, Jeremy Purcell ${ }^{2}$, Tsondue Samphel ${ }^{1}$, Tenzin Sonam ${ }^{1}$, \\ Karma Tenzin ${ }^{1}$, Dawa Tsering ${ }^{1}$, Carol M. Worthman ${ }^{3}$ and Arri Eisen ${ }^{4 *}$ \\ ${ }^{1}$ Center for Contemplative Science and Compassion-Based Ethics, Emory University, Atlanta, GA, United States, ${ }^{2}$ Maryland \\ Neuroimaging Center, University of Maryland, College Park, MD, United States, ${ }^{3}$ Department of Anthropology, Emory \\ University, Atlanta, GA, United States, ${ }^{4}$ Department of Biology, Emory University, Atlanta, GA, United States
}

\section{OPEN ACCESS}

Edited by:

Jen Schneider,

Boise State University, United States

Reviewed by:

Jennifer Peeples,

Utah State University, United States

Robert O'Malley,

American Association for the

Advancement of Science,

United States

*Correspondence:

Arri Eisen

aeisen@emory.edu

Specialty section: This article was submitted to

Science and Environmental

Communication,

a section of the journal

Frontiers in Communication

Received: 30 July 2019 Accepted: 18 December 2019

Published: 15 January 2020

Citation:

Gray KM, Namgyal D, Purcell J,

Samphel T, Sonam T, Tenzin K,

Tsering $D$, Worthman CM and Eisen $A$

(2020) Found in Translation:

Collaborative Contemplations of

Tibetan Buddhism and Western

Science. Front. Commun. 4:76.

doi: $10.3389 /$ fcomm.2019.00076
Development of an inclusive scientific community necessitates doing more than simply bringing science to diverse groups of people. Ideally, the sciences evolve through incorporation of diverse backgrounds, experiences, and worldviews. Efforts to promote inclusion of historically underrepresented racial, ethnic, cultural, religious, gender, and socioeconomic groups among science scholars are currently underway. Examination of these efforts yields valuable lessons to inform next steps in engaging diverse audiences with science. The Emory-Tibet Science Initiative may serve as one example of such efforts. The Dalai Lama invited Emory University to develop and teach a curriculum in Western science to Tibetan Buddhist monks and nuns. As the science curriculum has been taught and refined over the past decade, monastic scholars increasingly have taken ownership of the material. As Western scientific ideas and practices take hold in this setting, the experiences of monks and nuns offer unique insights into the process of translation, modes of communication, and long-term impacts of integrating diverse systems of knowledge. Given that the dominant language of science is English, Tibetan interpreters have been essential throughout the implementation of this project. Through the process of translating scientific terms, interpreters have considered differences in how words categorize, and therefore how people conceptualize, the world. Through comprehensive, culturally-responsive communication, scientific language is used as a tool to build and strengthen connections between monastics and their local and global communities. The intertwining of these complementary systems of knowledge iteratively informs translation, modes of communication, and broader impacts in the community.

Keywords: Tibetan Buddhism, audience-centered approach, strength-based approach, inclusive, science and religion dialogue, international science education, Dalai Lama, translation

The Dalai Lama invited Emory University to develop and teach a curriculum in Western science to Tibetan Buddhist monastics (Lama, 2005). In 2008, faculty traveled to Dharamsala, India to initiate a 6-year pilot. Annually, faculty taught physics, biology, and neuroscience (Eisen, 2011). Since 2014, a revised curriculum has been taught in three monastic universities (Eisen and Konchok, 2018). As of June 2019, all 6 years of the curriculum were active. The project is an ideal platform for exploration of cross-cultural science communication (Jinpa, 2010; Heuman, 2014; Gray and Eisen, 2019). As scientific ideas and practices take hold in this setting, the experiences of scientists and monastics offer unique insights into the process of translation, modes of communication, and long-term impacts of integrating diverse systems of knowledge. 
The dominant language of science is English; only a quarter of the monastics in the project understand at least half of the in-class English. Thus, Tibetan interpreters have been essential throughout the implementation of this project. Translating Western scientific ideas, concepts, and methods into a language and culture that has, until now, had minimal interaction with these principles is challenging. Even in a less complex setting, one might expect that some intended meanings would be lost or skewed during translation. While the Emory-Tibet Science Initiative (ETSI) translation team has found this to be true to some extent; much is also gained. The team has found in translation an expanded capacity to investigate differences in how words categorize, and therefore how people conceptualize, the world; to move beyond limits of word-to-word translation and into comprehensive, culturally-responsive communication; to motivate monastic students to use scientific language as a tool to build and strengthen connections with their local and global communities.

\section{TIBETAN TRANSLATION TRADITION}

In the eighth century, the Tibetan Emperor imported philosophy and practices from Nalanda and other Buddhist traditions in India (Huber, 2008). This not only brought knowledge of these different disciplines to Tibet, but also enriched the Tibetan language. Similarly, the Tibetan community is in the process of importing science into the Tibetan language; monastics are learning science and indigenous Tibetan scholars are writing treatises and integrating their own philosophical knowledge, reflection, and insights into the practice of science.

Eighth century Tibetan lo-tsawas (eyes of the world/translators) established translation guidelines with a list of examples accompanied by justifications for translations, detailed in the Dra-jor bam-nyis (Raine, $2010^{1}$ ). These general translation principles include: faithfully conveying content, maximizing resources in the target language, maintaining the spirit of the source; following syntactical rules of the target language, distinguishing between translating and editing, and aiming for a flowing rendition in the target language. These principles that shaped Tibetan translation of Buddhist texts over 1,000 years ago-ensuring integrity in meaning, language, and expressiveness-continue to guide science translation today.

These translation guidelines have been used for over a millennium, yet translation and creation of new terms remains challenging. The ETSI translation team has contributed over 5,000 scientific terms to the already rich Tibetan language in a collaborative process that combines traditional and twenty-first century approaches. The team identifies concepts that need to be clarified, considers Tibetan background knowledge and culture while selecting terms, and consults colleagues who have a variety of expertise.

\footnotetext{
${ }^{1}$ Toh 1523, Dege Tengyur, vol. co (sna-tshogs) page 131b-160B.
}

\section{Concepts}

The Nalanda tradition calls for creation of new words rather than defaulting to cognates. The addition of 5,000 scientific terms to the Tibetan language, and the evolving process used to create them, provides insights into the interplay between language, science, and Tibetan Buddhism. The ways society uses words to categorize the world-to divide and label our experiences of reality-varies by time, place, culture, and even academic discipline (Cruse, 1992). At first, simple translation seems as though it should suffice for words such as fire and water (Table 1). Other terms, such as quark, would be expected to require creation of a new Tibetan word. Life and consciousness call for careful explanation even in English, so these are destined to be translation challenges. It is untenable to create new terms for these concepts in Tibetan, as the current Tibetan terms are culturally and spiritually loaded.

Some terms such as fire and water have been fundamental to civilization for millennia. Their widespread use has pervaded their application in language colloquially, metaphorically, and scientifically (Taylor and Dewsbury, 2018). In saying there is a "fire in our heart," this does not referencing the narrow, scientific meaning of the rapid oxidation of material in an exothermic chemical process. The same is true for water; "water of life" does not refer to the molecular makeup of two hydrogen atoms and one oxygen atom. Scientific definitions provide specific meanings that constrain the terms in scientific dialogue for precise communication.

This issue is of particular confusion in Tibetan because terms like fire and water do not have well-established scientific meanings. In colloquial Tibetan, fire is a general term referring to that which produces heat and light. Therefore, one could say "the sun is a ball of fire" in Tibetan with correct meaning, although this phrase in the scientific sense would be incorrect, as the sun is a ball of gas undergoing nuclear fusion. Similarly, water in Buddhism may be used to describe anything that is wet, liquid, or flowing rather than referring to a specific chemical composition. Ultimately, scientific discoveries continuously produce and refine definitions to best reflect phenomena in the natural world.

In order for scientific Tibetan to have the level of precision of scientific English, new words must be introduced into the Tibetan lexicon. This provides a unique opportunity to coin words that may better reflect underlying scientific meanings than is present in current English. Ideally, such newly coined words will portray a sense of meaning for that term or concept from the word itself, without requiring specific background knowledge. Quark had no previous meaning itself in English (Mayer, 2018). The Tibetan translation is quark-dool; with quark having the pre-existing meaning of "innermost" and dool being the Tibetan word for "particle," thus suggesting the meaning of the full term (Table 1). This translation has the benefit of maintaining some sound of the English equivalent.

Precise definitions are even more important when considering complex concepts such as "life" (Table 1). Western introductory biology classes often begin with a definition of life based on lists of characteristics to classify something as living or non-living (Wilkin and Gray-Wilson, 2017). In Tibetan Buddhism, defining life is less clear. Life is translated as tshe-srog, which arguably 
TABLE 1 | Example scientific terms and how these were translated into Tibetan concepts.

\begin{tabular}{|c|c|c|}
\hline English term & Tibetan term & Translation explanation \\
\hline Fire & ओ & Distinguish between general heat and light and the scientific definition of combustion \\
\hline Water & क্ডু| & Distinguish between anything that is liquid and water molecules composed of hydrogen and oxygen \\
\hline Quark & 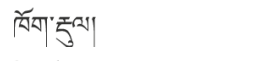 & Translated as "innermost particle" \\
\hline Life & के स्त्राया & $\begin{array}{l}\text { Distinguish between inclusion of consciousness in the definition of life and the scientific definition of life; } \\
\text { Translated as life energy/life force }\end{array}$ \\
\hline Life form & 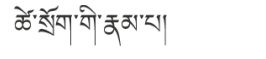 & Specifically referring to form(s) of life \\
\hline Sentience & 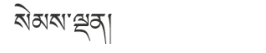 & Translated as "possessing mind" \\
\hline Cell body & 저ㅈㅓㅔ & Distinguish between cell-bodies and cell-minds i.e., Do scientists consider cells to have a "mind"? \\
\hline Body of a cell & इसुर बेंबुसा। & Central part of a cell i.e., Not the dendrites of a nerve cell \\
\hline Amygdala & 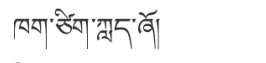 & Translated as "almond-shaped brain structure" \\
\hline Organism & 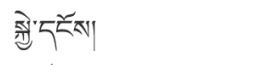 & Translated as "growing/developing thing" \\
\hline Mass & 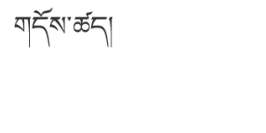 & 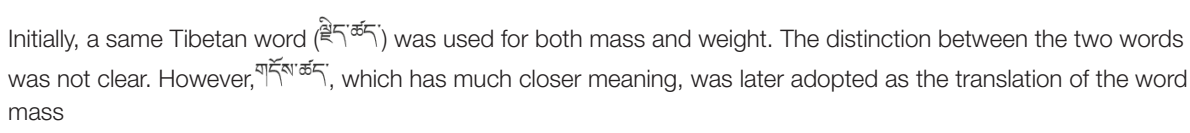 \\
\hline Weight & 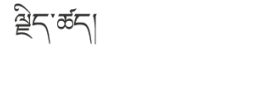 & $\begin{array}{l}\text { बेरे 'कॅ' is an equivalent term for weight. It is not a new term but it has acquired a finer definition because of the way } \\
\text { weight is understood in science }\end{array}$ \\
\hline Force, energy, power & 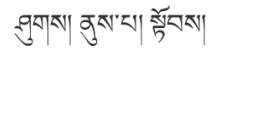 & $\begin{array}{l}\text { Although these three physics terms have distinct meaning, the three Tibetan terms had very similar meanings and } \\
\text { were used interchangeably. Now these three terms have acquired distinct meanings and are used more strictly, } \\
\text { especially amongst the monastic science students }\end{array}$ \\
\hline $\begin{array}{l}\text { Proton, neutron, } \\
\text { electron }\end{array}$ & 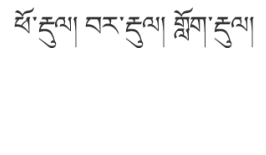 & 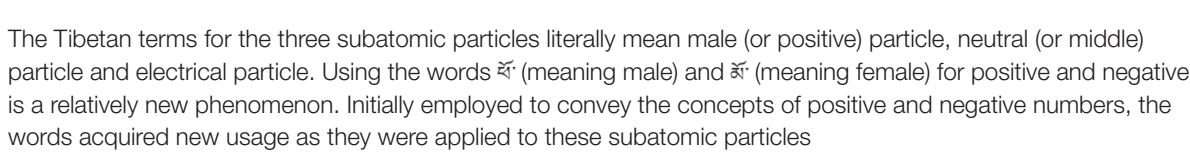 \\
\hline
\end{tabular}

relates to consciousness. This gets into problematic areas at the boundary of science and Buddhism, leading to questions such as: Are plants conscious? Are plants living? Are bacteria conscious? Are bacteria living? (Eisen and Konchok, 2018). One response for the translator is to differentiate living beings and living things; another, more daunting is to provide satisfactory answers in both Buddhism and science to the aforementioned questions.

Many scientific terms, especially those being generated at the forefront of research, have evolving definitions (McGee, 2004). The dynamic nature of such terms makes translation even more difficult. At the same time, this can inspire research questions. For example, translating names for functional regions of the brain facilitated debate of the evidence for such labels among neuroscientists. Cross-cultural linguistic dialogue may encourage increasingly precise ways of engaging science.

\section{Audience-Centered Communication}

Optimal communication interweaves knowledge of concepts and knowledge of the backgrounds and experiences of the receivers. It is important, therefore, to focus on how information is perceived by the audience, to understand the experience of delivering that information, to be truly present to the audience and deeply explore possible meanings before pinning down the one that best fits. Translators must move beyond maximizing technical precision at all times and instead ensure the intended audience understands concepts in-depth at every step.

One must have a thorough understanding of a topic in order to convey it to others; translating concepts adds an additional layer to that understanding. In a classroom setting, instructors may ask students to put lessons or concepts into their own words, rather than taking words directly from the instructor or the book. Educators can use principles of translation and audience-centric teaching to help guide students in processing information presented to them. This may involve providing space for literal translation from one language to another in multilingual classrooms or asking students to generate and share multiple interpretations of the same text or concept within one language. Variety in language captures nuances that are missed in other phrasings, so learning may be enhanced for multilingual students (Sieber, 2004). Conceptual descriptions in each language can complement one another; if one is unclear, the student may turn to the other language to clarify meaning.

\section{Communal Translation}

The importance of community in translation is emphasized when translating English science content into Tibetan as there is not a Tibetan spellcheck. To complicate matters further, Tibetan was spoken for centuries before being formally written 
(Laufer, 1918). Subtle differences in spelling can result in vastly different meaning.

Translators often contact the author of a text for clarification or engage with other translators to consider options. The primary translator meticulously reviews feedback. Technical terms that appear for the first time in ETSI translation history are tabled for consideration at the next Translation Conference.

Ten scientific Tibetan translation conferences have convened since 2009 with the goal of creation and standardization of a new scientific lexicon. ETSI has used this lexicon in 20 textbooks, thousands of PowerPoints, and in video lectures developed specifically for the monastic audience (Emory-Tibet Science Initiative, 2019). The conferences draw on the expertise of monastics, lay scholars of Buddhist philosophy, Tibetan medical doctors, and Tibetans trained in western science. The process involves understanding the etymology of the source text and ensuring the evolving lexicon is simple, versatile, and consistent with existing Tibetan lexicons and grammatical rules. ETSI translators use a dialectical debate system borrowed from monastic learning to reach deeper clarity and understanding of definitions in context. When considering the relationship between a neuron and a brain cell-Are they the same thing, i.e., co-extensive/interchangeable? Are they mutually exclusive with no common locus between them? Does one include the other, while the other does not? Alternatively, do they have a four-cornered relation, where one finds a brain cell that is also a neuron and vice versa, while at the same time there are neurons that are not brain cells and vice versa? Through such dialogues one can come to an understanding that there are more than just neurons in the brain and that neurons outside of the brain have some unique properties (e.g., ability to regenerate when damaged) that are not clearly present in brain neurons. Here the goals are precision and accuracy in generating a definition that is neither too broad nor too narrow.

\section{STRENGTH-BASED COMMUNICATION}

The 6-year ETSI science curriculum makes heavy use of translated texts, as most internet sources containing scientific content for the public are in English. Reading comprehension is a challenge in monastic science classrooms. The students have a wide variety of educational backgrounds, and some students have not studied reading and writing in Tibetan well enough to comprehend the science materials that have been translated into Tibetan.

To address this challenge, science instructors adapted preexisting monastic and Western pedagogical tools. For example, integration of science into traditional monastic debating. Each day's monastic Buddhism classes are followed by hours of evening debate where students alternately assume roles of challenger and defender (Tillemans, 1989) and draw on lessons from the day and their foundational knowledge to address the assigned topic while exploring their level of understanding.

In December 2015, Mind and Life Institute organized its 30th Mind and Life Dialogue at Sera Monastery. Monks from many monasteries gathered at Sera to listen to the conference. Taking advantage of this, a debate session was organized in which the ETSI monks were asked to debate on scientific topics such as visual perception and how it is formed, the dual nature of light and particles, and evolution. The group debate, held in Tibetan in the formal monastic style of debate, was presented to His Holiness the Dalai Lama and scientists. This debate, the first of its kind, generated much excitement and was possible because of programs such as ETSI.

Concrete examples, things one can see, feel, and experience, are beneficial for conveying ideas. This has been an especially important practice in communicating math concepts. As even the simplest mathematical equations are somewhat abstract, using examples from everyday life, such as how many rupees a cup of tea costs, is essential.

Presentation of science via multimedia formats in digestible chunks helps communicate information in ways that can be shared widely (Guo et al., 2014). Considering the interest of students in connecting their experiences, and what they have learned, with their networks, this is an excellent strategy to deliver lessons while tapping into their motivations for engaging with the content in the first place. Students have taken ownership of this strategy and initiated minute-long science talks that are shared in group messages and followed by debate. Some students have even written science-inspired poems (Figure 1).

Multiple modes of assessment reveal a more holistic understanding of student knowledge and application than can be detected by exams alone (Tal, 2005). Given the reading comprehension challenges in monastic classes, providing students with diverse opportunities to demonstrate learningpresentations, discussions, journals (Balgopal et al., 2017)-has proven even more important.

\section{COMMUNITY CONNECTION}

Effective science communication in education should extend beyond the boundaries of classroom walls. Teachers can challenge students to prepare for applying and extending their knowledge as global citizens though cross-cultural linguistic scientific dialogue (Ruano et al., 2014). Given that some western students have the conception that science is predominantly a solitary activity (Palmer, 1997), it is especially important to provide opportunities for students to realize the vast possibilities for human connection that science creates.

\section{Local Learning/Global Growth}

Monastics play an important role in the usage and spread of new terminology, especially newly coined Tibetan scientific words. When the monks and nuns take science classes in addition to their monastic studies, they use the Tibetan science terminology among their fellow monastics. 1496 monks from nine monasteries and 41 nuns from five nunneries have participated in ETSI summer intensive workshops. The ETSI curriculum is now included as part of the core monastic studies and is a required part of Gelug examinations - the examination for the Geshe Lharam degree, the highest monastic degree and equivalent to a western doctorate (Gray and Eisen, 2019).

Most of the large monasteries have been established near Tibetan settlements in exile to maintain strong connections between spiritual leaders in the Buddhist community and 


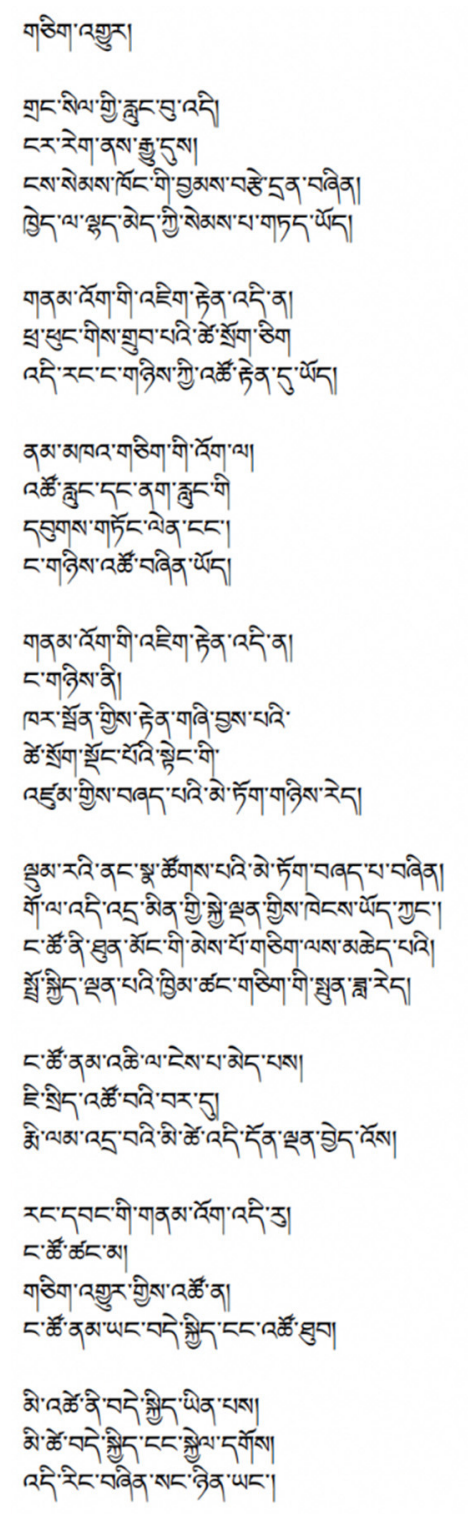

Oneness

When this cold wind

Touches me and passes through

I recall my inner love and

Send you my warming heart waves.

Under this same sky

Today we have a life to live

a life made up of cells.

Under the same sky

we respirate

The same oxygen and $\mathrm{CO}_{2}$

Under the same sky

We are blossoming flowers

Of a carbon-based life tree.

Like a diverse flower in a garden,

The earth is full of a different life.

But, we are a member of the happy family;

a descendant of a common ancestor.

The strength of life is unknown

We should make it meaningful

Hence we have it like a dream.

In this open sky,

We all rise to live.

To be oneness,

and we live happily together

Forever and ever.

Life is beautiful

Live it beautifully

As it is today.

FIGURE 1 | Poem authored by Stanzin Wangdan, one of the 2017-2019 Tenzin Gyatso Scholars who completed a 2-year science residency at Emory University.

lay members of the community. As monastics interact with local Tibetans during talks, teachings, and other academic conversations, they naturally begin to integrate science terminology that has been used in their coursework. This has sparked interest in science through a language the community can understand. Monastics have created social media groups, that include the lay Tibetan community, to discuss scientific concepts. Some of these include up to 500 members. This has also been accomplished through formalized science events hosted by monasteries and nunneries. In these ways, the use of new terminology reaches large numbers of people relatively quickly. This also serves to further the goal of fostering exchange between Tibetan Buddhism, language, culture, and history and the tradition of Western science (Eisen, 2011; Eisen and Konchok,
2018; Gray and Eisen, 2019). As there are more opportunities for engagement with the community outside of the monastery, Tibetan science language will be used in more ways that allow for it and the corresponding science to grow.

With their increasing engagement in science, monastics have begun to collaborate with ETSI scientists in original scientific research related to the greater Tibetan community. Neuroscience research investigating brain activity during monastic debate has been published and featured in news articles (Lakshmi, 2017; van Vugt et al., 2018). Western scientists have published their findings and discourse related to the initiative in professional journals, such as Zebrafish (Kimelman, 2018). In 2016, Gaden Shartse Monastic Science Center started an annual journal called Drops of Ancient and Modern Science, which contains articles 
on modern science and Buddhist science. Public health projects related to diabetes, depression, and water quality have been initiated in the monastic communities. These research projects are just one method of building meaningful connections with local and global communities that may open up new solutions and areas of inquiry.

\section{A 100-YEAR PROJECT}

This project serves as a model for broad cross-cultural science engagement. A range of bilingual, culturally relevant communication materials have been created throughout the lifetime of this initiative including textbooks, video lectures, and presentation slides. This work can be applied in other contexts through consideration and adaptation of the approach to science communication employed by ETSI. For example, the variety of educational materials generated are intended to reach a diverse group of learners including those in formal educational settings and those in the general public.

Ideally, science evolves through incorporation of diverse backgrounds, experiences, and worldviews that stimulate new directions, innovation, and creativity. ETSI fosters productive exchange between science and Tibetan Buddhist culture and knowledge. As this partnership takes root and blossoms, this will give rise to its own reflections and its own insights. This takes time. The Dalai Lama has called this a 100 -year project.

ETSI looks to connect the multicultural nature of society and the ways we communicate science to advance

\section{REFERENCES}

Balgopal, M. M., Wallace, A. M., and Dahlberg, S. (2017). Writing from different cultural contexts: How college students frame an environmental SSI through written arguments. J. Res. Sci. Teach. 54, 195-218. doi: 10.1002/tea.21342

Cruse, D. A. (1992). Cognitive linguistics and word meaning: Taylor on linguistic categorization. J. Linguistics 28, 165-183. doi: 10.1017/S0022226700015048

Eisen, A. (2011). What Buddhist monks taught me about teaching science. The Chronicle of Higher Education. Available online at: https://www.chronicle.com/ article/What-Buddhist-Monks-Taught-Me/129697

Eisen, A., and Konchok, Y. (2018). The Enlightened Gene: Biology, Buddhism, and the Convergence that Explains the World. Lebanon, NH: ForeEdge.

Emory-Tibet Science Initiative (2019). Available online at: https:// emorytibetscienceinitiative.com

Gray, K. M., and Eisen, A. (2019). The emory-tibet science initiative: rethinking cross-cultural science and teaching. J. Microbiol. Biol. Educ. 20. doi: $10.1128 /$ jmbe.v20i1.1618

Guo, P. J., Kim, J., and Rubin, R. (2014). "How video production affects student engagement: an empirical study of MOOC videos," in Proceedings of the First ACM Conference on Learning@ Scale Conference (ACM), 41-50.

Heuman, L. (2014). Under one umbrella: can tradition and science both fit? An interview with Thupten Jinpa Langri. Tricycle 23, 74-79; 108-111. Available online at: https://tricycle.org/magazine/under-one-umbrella- $2 /$

Huber, T. (2008). The Holy Land Reborn: Pilgrimage and the Tibetan Reinvention of Buddhist India. Chicago, IL: University of Chicago Press.

Jinpa, T. (2010). Buddhism and science: how far can the dialogue proceed? Zygon 45, 871-882. doi: 10.1111/j.1467-9744.2010.01138.x

Kimelman, D. (2018). Ground, path, and fruition: teaching zebrafish development to Tibetan Buddhist Monks in India. Zebrafish 15, 648-651. doi: 10.1089/zeb.2018.1657 a holistic understanding of the human condition. We have already begun to see how the intertwining of these complementary systems of knowledge creates positive feedback loops that continually inform translation, modes of communication, and broader impacts in the community.

\section{AUTHOR CONTRIBUTIONS}

$\mathrm{KG}, \mathrm{CW}$, and $\mathrm{AE}$ contributed conception and design of the article. KG wrote the first draft of the manuscript. DN, JP, TSa, TSo, KT, and DT wrote sections of the manuscript. All authors contributed to manuscript revision, read, and approved the submitted version.

\section{FUNDING}

Dalai Lama Trust (Tenzin Gyatso Scholar's living expenses at Emory), Templeton Foundation (Summer intensive teaching program at monasteries), and Joni Winston.

\section{ACKNOWLEDGMENTS}

We would like to thank Geshe Lobsang Tenzin Negi and the entire Center for Contemplative Science and Compassion-based Ethics at Emory University for their support. We are grateful for the Dalai Lama and his vision for the convergence of science and Tibetan Buddhism.

Lakshmi, S. (2017, August 14). Picking the brain of a monk: where buddhism claps its hands for science. The Times of India.

Lama, D. (2005). The Universe in a Single Atom: The Convergence of Science and Spirituality. Harmony.

Laufer, B. (1918). Origin of tibetan writing. J. Am. Orient. Soc. 38, 34-46. doi: $10.2307 / 592582$

Mayer, J. (2018). The Origin of the Word 'Quark'. Science Friday. Available online at: https://www.sciencefriday.com/articles/the-origin-of-the-word-quark/

McGee, G. (2004). "Embryonic stem cell research, nationalism, and transplantation," in Ethical, Legal, and Social Issues in Organ Transplantation, eds T. Gutmann, A. S. Daar, R. A. Sells, and W. Land (Lengerich: Pabst Science Publishers), 101-123.

Palmer, D. H. (1997). Investigating students' private perceptions of scientists and their work. Res. Sci. Technol. Educ. 15, 173-183. doi: 10.1080/0263514970150204

Raine, R. (2010). "The translator in Tibetan History," in FORUM. Revue Internationale D'interprétation et de Traduction/International Journal of Interpretation and Translation, Vol. 8 (John Benjamins), 133-161.

Ruano, J. C., Galeffi, D. A., and Ponczek, R. L. I. (2014). The cosmodernity paradigm: an emerging perspective for the global citizenship education proposed by UNESCO. Transdiscipl. J. Eng. Sci. 5, 21-34. doi: $10.22545 / 2014 / 00056$

Sieber, T. (2004). "Excelling in the critical study of culture: the multilingual-multicultural student advantage,: in Crossing the Curriculum: Multilingual Learners in College Classrooms, $129-144$.

Tal, T. (2005). Implementing multiple assessment modes in an interdisciplinary environmental education course. Environ. Educ. Res. 11, 575-601. doi: $10.1080 / 13504620500169767$ 
Taylor, C., and Dewsbury, B. M. (2018). On the problem and promise of metaphor use in science and science communication. J. Microbiol. Biol. Educ. 19. doi: 10.1128/jmbe.v19i1.1538

Tillemans, T. J. (1989). Formal and semantic aspects of Tibetan Buddhist debate logic. J. Indian Philos. 17, 265-297. doi: 10.1007/BF00207294

van Vugt, M. K., Pollock, J., Johnson, B., Gyatso, K., Norbu, N., Lodroe, T., et al. (2018). Inter-brain synchronization in the practice of Tibetan monastic debate. MindRxiv. doi: 10.31231/osf.io/f2ept

Wilkin, D., and Gray-Wilson, N. (2017). Characteristics of Life. Available online at: https://www.ck12.org/biology/Characteristics-of-Life/lesson/ Characteristics-of-Life-Advanced-BIO-ADV/
Conflict of Interest: The authors declare that the research was conducted in the absence of any commercial or financial relationships that could be construed as a potential conflict of interest.

Copyright (C) 2020 Gray, Namgyal, Purcell, Samphel, Sonam, Tenzin, Tsering, Worthman and Eisen. This is an open-access article distributed under the terms of the Creative Commons Attribution License (CC BY). The use, distribution or reproduction in other forums is permitted, provided the original author(s) and the copyright owner(s) are credited and that the original publication in this journal is cited, in accordance with accepted academic practice. No use, distribution or reproduction is permitted which does not comply with these terms. 